\title{
Pattern of arterial involvement of the head, neck, and eyes in giant cell arteritis: three case reports
}

\author{
Z Butt, J F Cullen, E Mutlukan
}

\begin{abstract}
The findings of two post-mortem examinations and one CT scan of patients with biopsy proved giant cell arteritis (GCA) are presented. The presence or absence of intracranial involvement in GCA is discussed.
\end{abstract}

Giant cell arteritis (GCA) is rarely fatal, and references to the condition in post-mortem material are uncommon..$^{1-16}$ However, this may be related to non-recognition of a fatal outcome in patients with GCA and because post-mortem examinations of elderly patients dying from vascular disorders are not routinely carried out. GCA may be concealed among the cases diagnosed as ischaemic catastrophes due to arteriosclerosis. ${ }^{17}$

Patients suffering from GCA have a range of symptoms including headache, jaw claudication, fever, anorexia, and loss of vision. However, atypically they may present with symptoms of cerebral ischaemia, the aetiology of which may be confused with that of other conditions such as arteriosclerosis. We suggest that such atypical symptoms may be secondary to embolism and that the diagnosis of GCA should not be overlooked. A raised erythrocyte sedimentation rate together with positive findings on temporal artery biopsy should help in confirming or refuting the diagnosis. GCA is treatable, and treatment leads to symptomatic improvement.

\section{Case reports}

\section{CASE 1}

An 80-year-old man presented in 1973 with a three-month history of temporal headaches, influenza-like symptoms, and anorexia. Acute loss of vision in the right eye had occurred two days previously and acute loss of vision in the left eye followed on the day of presentation. Visual acuity was no perception of light in the right eye and perception of light in the left eye. His pupils did not react to light, and there was bilateral oedema of the discs. The Westergren erythrocyte sedimentation rate was $90 \mathrm{~mm} / \mathrm{h}$. Anterior ischaemic optic neuropathy secondary to GCA was diagnosed, and high-dose corticosteroid treatment was initiated. His mental condition deteriorated over the next few days, and he was thought to have sustained a cerebrovascular accident. He became comatose and died secondary to hypostatic pneumonia. His temporal arteries at necropsy showed characteristic changes of GCA (see below).

Post-morten findings. Macroscopically the main arteries at the base of the brain were virtually free from atheroma, but a plug of rather firm clot was present in the stump of the right internal carotid. The circle of Willis was normally constituted. Several haemorrhagic infarcts were noted in the cerebrum (frontal, parietal, temporal, and occipital lobes) and cerebellum. Microscopic examination confirmed that these were very recent, practically terminal, infarcts. Occasionally small meningeal arteries overlying the cortical infarcts were noted to contain recent thrombus, but in none of the sections was there evidence of giant cell arteritis.

Sections of the temporal, ophthalmic, vertebral, internal carotid (in neck), external carotid, left common carotid, and coronary arteries showed changes typical of giant cell arteritis. Histological abnormalities noted included: (1) Diffuse fibrous thickening of the intima associated with mucinous changes and narrowing or occlusion of the lumen. (2) The presence of organising mural thrombus (both internal carotid arteries). (3) Fragmentation and disappearance of the internal elastic lamina. (4) Chronic inflammatory changes which were transmural but principally involved the media, especially in relation to damaged internal elastic lamina.

The inflammatory cell infiltrate was predominantly composed of lymphocytes and epithelioid cells along with a few plasma cells and variable numbers of Langhans giant cells. Foci of fibrinoid degeneration were seen in the deeper layers of the fibrosed intima and in the media in some sections. In many of the affected vessels severe atheroma complicated the histological picture. The terminal segment of the right internal carotid artery showed no evidence of GCA, containing only red blood clot (not thrombus).

Examination of the globes showed: (1) Oedematous optic discs but normal and patent central retinal vessels. (2) Infarction in the retrolaminar region of the optic nerve (Figs 1 and 2). (3) Chronic inflammatory changes of the adjacent posterior ciliary arteries. Many of the vessels were occluded.

CASE 2

An 86-year-old woman presented in June 1988 with an eight-day history of loss of vision in her 
Figure 1 Histological section of right optic nerve. $(H-E$ and eosin stain, $\times 20$.)

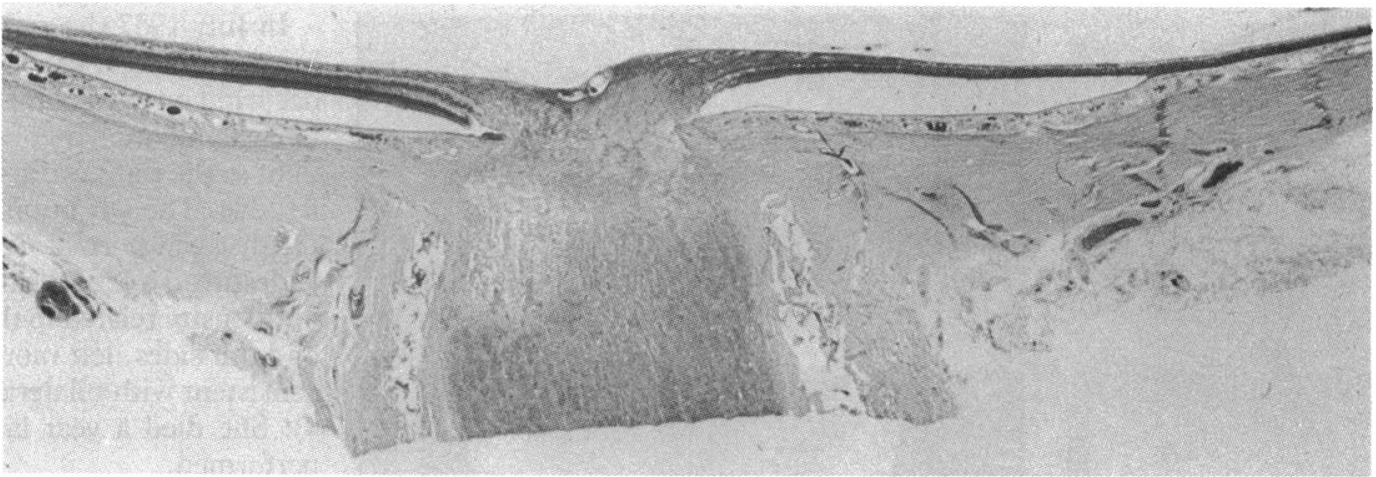

right eye. This was associated with decreased appetite, weakness, jaw claudication, general malaise, and shoulder stiffness.

She had had a right cataract extraction with intraocular lens implant in August 1987. She was dependent on her right eye for vision because her left eye had a dense cataract. Visual acuity was $6 / 60$ in the right eye and perception of light in the left. The right pupil was unreactive to light, but pupil adhesions to the anterior vitreous were present. The left pupil reacted sluggishly to light. Her optic discs were pale but not swollen. She had a total bilateral ophthalmoplegia. The patient did not co-operate for visual field testing. A provisional diagnosis of posterior ischaemic optic neuropathy was made at this time.

The Westergren ESR was $110 \mathrm{~mm} / \mathrm{h}$, and high dose corticosteroid treatment was started. The diagnosis of GCA was confirmed by temporal artery biopsy. $X$-rays of the skull, optic foramina, and pituitary fossa were normal. Unfortunately there was further visual reduction to no perception of light in the right eye and perception of light in the left eye.

A CT scan suggested symmetrical cortical infarctions round the calcarine fissure, features consistent with cortical blindness (Fig 3). However, this was not confirmed by post-mortem examination performed three months later (see below).

In September 1988 she had a massive gastrointestinal haemorrhage, probably a complication of high-dose steroid treatment, and died.

Post-mortem findings. Microscopically, sections of the cerebral cortex and basal ganglia showed a few tiny old infarcts. The calcarine cortices were normal. Neither the arteries on the surface of the brain and subarachnoid space nor within the brain substance showed any evidence of arteritis. The carotid bifurcations were grossly atheromatous but not particularly stenosed. One or two small arterial twigs in the surrounding connective tissue were thick walled, had probably been thrombosed, and showed sparse lymphocytic infiltration of their walls, most marked in the adventitia. No giant cells were identified in relation to the internal elastic lamina. Similar changes were present in the arterial twigs accompanying the optic nerves, including the ophthalmic artery but not the central retinal artery. A solitary microscopic infarct was present in the right optic nerve in the retrolaminar region. Thus

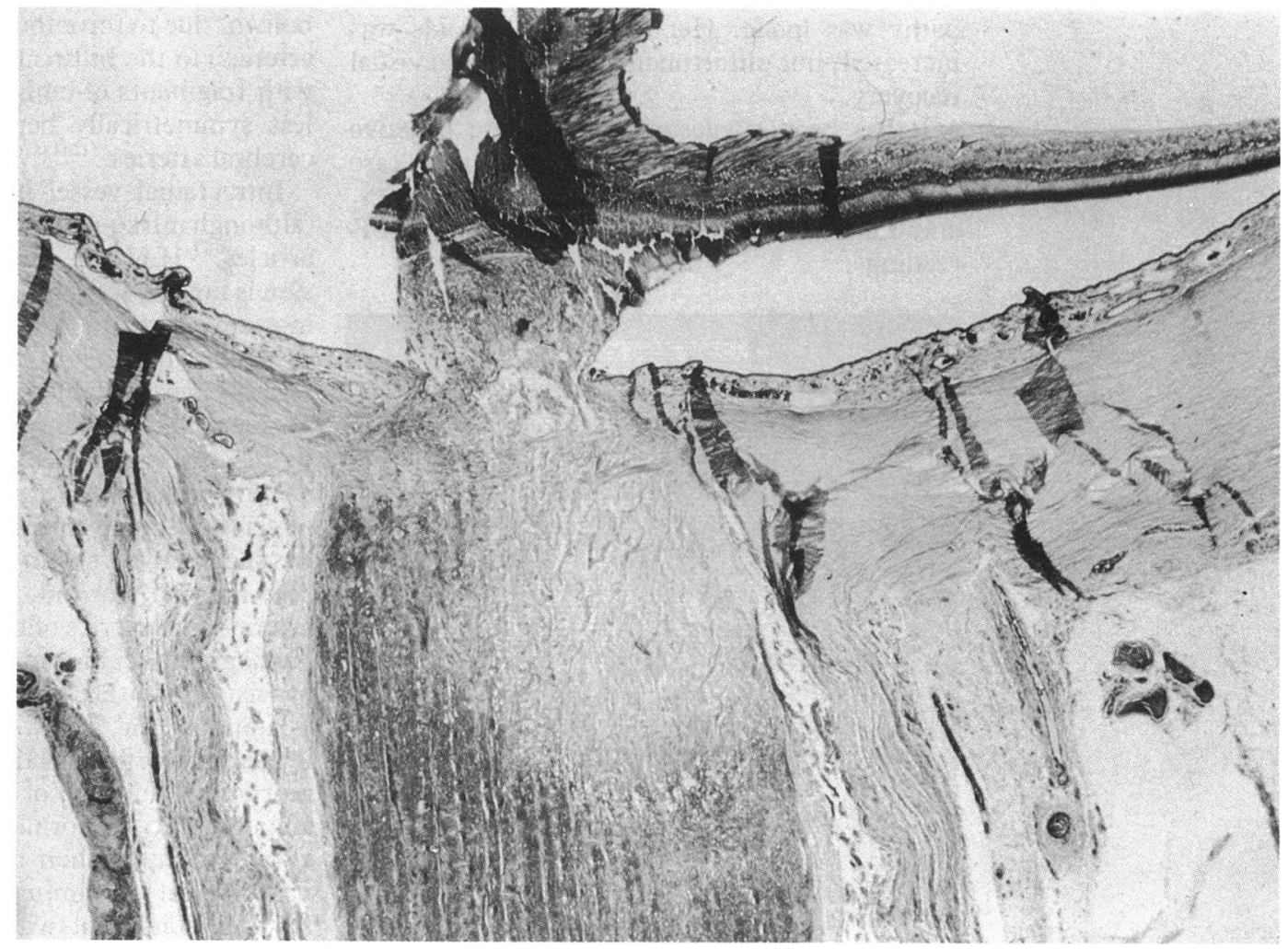


Figure 3 Case 2. CT scan.

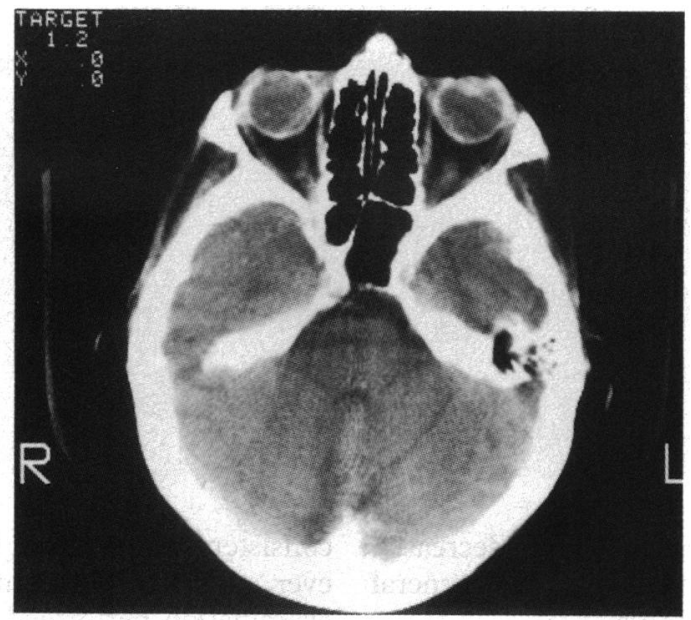

these chronically inflamed scarred small arteries were considered to represent a burnt out version of GCA.

\section{CASE 3}

A 65-year-old woman presented in 1964 with a three-week history of severe frontal headache associated with temporal tenderness. There were no ocular symptoms and her vision was normal The Westergren ESR was $83 \mathrm{~mm} / \mathrm{h}$, and biopsy of her right temporal artery showed classical changes of GCA. Corticosteroid treatment was started and led to symptomatic improvement.

Seven years later, while still on carefully monitored treatment, she presented with an episode of visual loss in the right eye, acuity falling from previously recorded $6 / 6, \mathrm{~N} 5$, to $6 / 60, N 18$. She had a right afferent pupillary defect and a swollen pale disc. The ESR was 45 $\mathrm{mm} / \mathrm{h}$. Details up to this time were reported by Cullen. ${ }^{18} \mathrm{~A}$ repeat right temporal artery biopsy showed no evidence of active arteritis. A diagnosis of right anterior ischaemic optic neuropathy was made. Her dosage of steroids was increased, but unfortunately there was no visual recovery.

It has been suggested that despite negative temporal artery biopsies ${ }^{18}$ the disease in this case remained active in the posterior ciliary arteries, and this was reflected by moderately raised ESR readings.

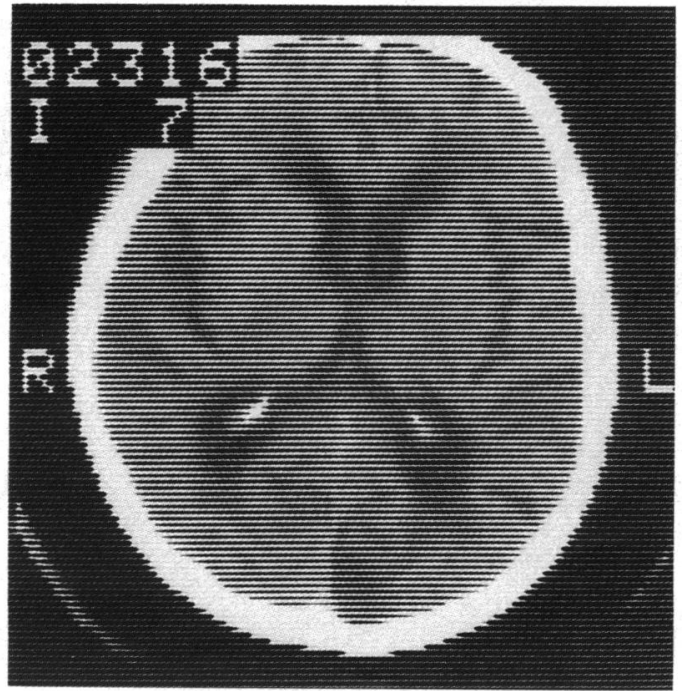

In July 1987 she was seen again with a 10-day history of loss of vision in her left eye which had occurred on awakening. The ESR was $75 \mathrm{~mm} / \mathrm{h}$. On examination her vision was perception of light in the right eye and hand movements in the left eye. The left pupil was reactive to light and the disc was normal. A CT scan showed marked widespread cortical atrophy and focal areas of low density related to the tip of the occipital pole on both sides, left more than right, which were consistent with bilateral occipital infarction (Fig 4). She died a year later. A necropsy was not performed.

\section{Discussion}

In our three patients changes typical of GCA were present in the temporal arteries, proved by temporal artery biopsy in cases 2 and 3 and by positive histological changes in the post-mortem examination of the superficial temporal and other arteries in case 1. Necropsy carried out on two patients with proved cerebrovascular disease related to GCA failed to identify intracranial GCA. The cerebral infarcts found were the results of embolism from extracranial vessels, which were damaged by arteritis and atheroma and contained thrombus, rather than from lesions of the intracerebral arteries themselves. This was confirmed by the multiple, haemorrhagic nature of the lesions.

In case 3 there was evidence of cerebral involvement on CT scan. However, it is not possible to say whether this was due to lesions of the intracranial or extracranial vessels. This case therefore neither confirms nor contradicts our initial hypothesis that cerebrovascular disease in GCA may not be due to intracranial arteritis. However, whatever the pathogenesis of this patient's condition, it must allow for the possibility of simultaneous infarction of both occipital lobes. The simplest explanation would be embolism (due to thrombus from arteritic vertebral arteries) to the bifurcation of the basilar artery, with fragments of embolus being shed more or less symmetrically between the two posterior cerebral arteries. ${ }^{721415}$

Intracranial vessel involvement is suggested (although infrequently) in a number of published articles. ${ }^{1-9}$ However, the basis for such a conclusion is not always certain. There is clinical, postmortem, and angiographic support for intracranial involvement, but post-mortem studies are the most reliable source of information, as angiographic and clinical evidence may be open to the criticism that coincidental arteriosclerosis or some other disease process could be the cause of cerebral involvement. Post-mortem evidence has shown involvement of the intracranial part of the internal carotid, vertebral, and basilar arteries and arteries of the base of the brain. ${ }^{12579}$ Angiographic abnormalities have been noted consisting of either irregular areas of stenosis and dilatations ${ }^{10}$ or a saw-toothed appearance ${ }^{6}$ in intracranial arteries. Hinck et $a l^{10}$ found no postmortem evidence of GCA related to the angiographic abnormalities, whereas Hirsch et $a l^{6}$ confirmed their angiographic findings by pathological examination, which showed features consistent with GCA in the anterior, 
middle cerebral, and entire part of the basilar artery. The authors suggest that angiographic abnormalities may in fact be non-specific and related to embolic phenomena, thrombi, or atheroma, and may not always be conclusive of intracranial pathology due to GCA. ${ }^{11}$ Similar cerebral angiographic findings have been reported in other types of arteritis such as polyarteritis nodosa, rheumatoid arthritis, and systemic lupus erythematosus. ${ }^{6}$

In two reports, ${ }^{34}$ in contrast to those already mentioned, there does appear to be post-mortem evidence for intracranial involvement of smaller cerebral vessels. However, in one of these reports the findings relate to minor changes in small vessels (with dubious symptomatic consequences), ${ }^{3}$ and in the other instance the clinical features are not entirely characteristic of GCA and another diagnosis cannot be excluded. ${ }^{4}$ Such changes may in fact be the result of other conditions such as polyarteritis nodosa, Buerger's disease (endarteritis obliterans), tuberculosis, and Takayashu's syndrome (pulseless disease). ${ }^{7}$ In these four conditions giant cells with inflammatory changes have been noted in pathological specimens, but clinical symptoms and signs help to differentiate them from GCA. However, signs and symptoms occasionally overlap owing to similar sites of involvement. ${ }^{\text {? }}$

A considerable literature tends to support our findings. ${ }^{11-1618}$ Extracranial vertebral artery and internal carotid artery involvement has been noted, giving rise to cerebral manifestations either through thromboembolic episodes, direct extension of thrombus from the site of arteritis into the artery of supply, or by reduced vertebral artery perfusion aggravated by concomitant arteritic or non-arteritic involvement of the internal carotids or insufficiency of the circle of Willis.

The vertebral arteritic changes reported by Crompton $^{3}$ and Wilkinson and Russell ${ }^{12}$ were noted to have a sharply defined upper border about $5 \mathrm{~mm}$ above the point of dural perforation. The terminal segment of the internal carotid artery within the dura was never involved..$^{12-14}$ This was thought to reflect the close correlation between susceptibility of GCA and the amount of elastic tissue in the media and adventitia of the individual arteries of the head and neck, as GCA is thought to be an autoimmune reaction involving arterial elastic tissue. Major transformation in the arterial muscle coats occurs as they enter the skull, with a gross diminution in the amount of elastic tissue. Intracranial arteries may be spared owing to the presence of little or no elastic tissue in their coats. ${ }^{12}$ This would also explain our pathological findings in the optic nerves, which showed infarction in the retrolaminar region due to GCA affecting the posterior ciliary arteries. In both of our post-mortem examinations the central retinal vessels were patent.

Cullen ${ }^{19}$ and MacFaul ${ }^{20}$ have reported in another case a similar picture of involvement of the posterior ciliary arteries and of the origin of the central retinal artery outside the globe and outside the optic nerve. The central retinal artery within the optic nerves as well as the retinal vessels within the globe and the choroidal vessels were all patent. This is important in view of the fact that the wall of the central retinal artery within the optic nerve contains very little elastic tissue (in contrast to considerably more in the walls of the ophthalmic and posterior ciliary arteries, ${ }^{12}$ and the internal elastic lamina ceases as the central retinal artery emerges from the disc.

We are greatly indebted to Dr A F J Maloney and Dr A Gordon of the Pathology Department. We also thank Mrs M Marshall for her many hours of secretarial assistance and Mr S Gairns, medical photographer, for his assistance with the prints.

1 Save-Soderbergh J, Malmvall BE, Anderson R, Bengtson BA. Giant-cell arteritis as a cause of death. $\mathcal{F A M A} 1986 ; 255$ : 493-6.

2 Kjeldsen MH, Reske Nielson E. Pathological changes of the central nervous system in giant-cell arteritis. Acta Ophthal$\operatorname{mol}(K b h) 1967 ; 46: 49-56$.

3 Crompton MR. The visual changes in temporal (giant-cell) arteritis. Brain 1959; 82: 377-90.

4 McCormick HM, Neubuerger KT. Giant-cell arteritis involving small meningeal and intracerebral vessels. $\mathcal{F}$ Neuropathol Exp Neurol 1958; 17: 471-8.

5 Morrison AN, Abitbol M. Granulomatous arteritis with myocardial infarction: a case report with autopsy findings. Ann Intern Med 1955; 42: 691-700.

6 Hirsch M, Mayersdorf A, Lehmann E. Cranial giant cell arteritis. Br f Radiol 1974; 47: 503-6.

7 Heptinstall RH, Porter KA, Barkley H. Giant-cell (temporal) arteritis. F Pathol 1954; 67: 507-18.

8 Gilmour JR. Giant-cell chronic arteritis. F Pathol 1941; 53: 263-77.

9 McMillan GC. Diffuse granulomatous aortitis with giant cells. Arch Pathol 1950; 49: 63-9.

10 Hinck VC, Carter CC, Rippey JG. Giant-cell cranial arteritis: a case with angiographic abnormalities. $A 7 R$ 1964; 92: 76975 .

11 Meadows SP. Temporal or giant-cell arteritis. Proc $R$ Soc Med 1966; 59: 329-33

12 Wilkinson I, Russell RW. Arteries of the head and neck in giant cell arteritis. Arch Neurol 1972; 27: 378-91.

3 Spencer WH, Hoyt WF. A fatal case of giant-cell arteritis with ocular involvement. Arch Ophthalmol 1960; 64: 862-7.

14 Chisholm IH. Cortical blindness in cranial arteritis. $\mathrm{Br} 3$ Ophthlamol 1975; 59: 332-3.

15 Symonds C, Mackenzie I. Bilateral loss of vision from cerebral infarction. Brain 1957; 80: 415-53.

16 Monteiro LRM, Coppeto JR, Greco P. Giant-cell arteritis of the posterior cerebral circulation presenting with ataxia and ophthalmoplegia. Arch Ophthalmol 1984; 102: 407-9.

17 Nordberg E, Bengtsson BA. Death rates and causes of death in 284 consecutive patients with GCA confirmed by biopsy. 284 consecutive patients

18 Cullen JF, Temporal arteritis: occurrence of ocular complications 7 years after diagnosis. Br $\mathcal{F}$ Ophthalmol 1972; 56: 584

19 Cullen JF. Occult temporal arteritis. Trans Ophthalmol Soc UK 1963; 83: 725-36.

20 MacFaul PA. Ciliary artery involvement in giant cell arteritis. Brf Ophthalmol 1967; 51: 505-12. 